\title{
Incorporação das ciências sociais na produção de conhecimentos sobre trabalho e saúde
}

\author{
Incorporation of the social sciences in the \\ production of knowledge about work and health
}

Carlos M inayo-Gomez 1

Sonia M aria da Fonseca Thedim-Costa 1

1 Centro de Estudos da Saúde do Trabalhador e Ecologia Humana, Escola Nacional de Saúde Pública, Fiocruz. Rua Leopoldo Bulhões 1480, $M$ anguinhos, 21041-230, Rio de Janeiro RJ. minayogo@ensp.fiocruz.br
Abstract This article presents a bibliographical revision on the influence of the social sciences to overcome the reducing conceptions of relationship work-health, in the last two decades. It is a type of diagnosis of the scientific production, in which outstanding aspects are: the contributions for the characterization of the worker's health, as knowledge field and of intervention, and for the analysis of the politics and of the practices of the public institutions; the comprehensive approaches and gender questions. It was conducted an assessment of indexed journals and masters degree dissertations and doctoral thesis. It was consulted: the bank of dissertations and thesis organized by the Coordination of I mprovement of the Higher Education and for the Brazilian Institute of Information in Science and Technology; the Virtual Library in $\mathrm{H}$ ealth of the Regional Library of M edicine and Scientific Electronic site O nline Library. It was verified the predominance of studies on specific themes and certain categories of workers, in opposition to attempts of totalizing approaches. In spite of the outstanding progresses in knowledge terms and of enlargement of study objects, significant lack of investigations exists on segments of the working population that present larger social vulnerability.

Key words Worker's health, Social sciences and worker's health, H umanities and worker's health
Resumo Este artigo apresenta uma revisão bibliográfica sobrea influência das ciências sociais para a superação de concepções reducionistas de relação trabal ho- saúde, nas duasúltimas décadas. Trata-se de um tipo de diagnóstico da produção científica, no qual destacamse: as contribuições para a caracterização da saúde do trabalhador, como campo de conhecimento e de intervenção, e para a análise da política e das práticas das instituições públicas; as abordagens compreensi vas e as questões de gênero. Efetuou-se um levantamento de artigos de periódicos indexados e de dissertações e teses de pós-graduação. Foram consultados: 0 banco de dissertações e teses da Coordenação de A perfeiçoamento do Ensino Superior e do Instituto Brasileiro de Informação em Ciência eTecnologia; a Biblioteca Virtual em Saúde da Biblioteca Regional de M edicina e o site do Scientific Electronic Library O n-line. Constatou-se a predominância de estudos sobre temáticas específicas e determinadas categorias de trabalhadores, em contraposição a tentativas de abordagens totalizadoras. A pesar dos notáveis avanços em termos de conheci mento, existe carência si gnificativa de investigações sobre segmentos da população trabalhadora que apresentam maior vulnerabilidade social. Palavras-chave Saúde do trabalhador, Ciências sociais e saúde do trabalhador, Ciências humanas e saúde do trabalhador 


\section{Introdução}

A incorporação das ciências sociais na produção de conhecimentos sobre a relação trabaIho-saúde adquire um novo enfoque, a partir dos anos 70 do século passado, em decorrência do entendimento do processo saúde-doença introduzido pela M edicina Social Latino-Americana. Sob o primado das teorias da determinação social, colocou-se em foco a rel evância do trabalho na reprodução social das populações. No Brasil, dentro do processo da reforma sanitária, a problemática da atenção à saúde dos trabalhadores passou a fazer parte das atribuições próprias da saúde pública.

0 sal to qualitativo, que permitiu apreender a complexidade das questões relativas à saúde dos trabal hadores, se deu com a apropriação do conceito nucleador de processo de trabalho, extraído da economia política, na sua acepção marxista. Esse conceito passou a constituir referência central e um sólido alicerce para o entendimento dos padrões de desgaste dos trabaIhadores no marco dinâmico do processo de valorização do capital (Laurell, 1985). A utilização do referido conceito em toda a sua extensão que inclui contemplar a subjetividade dos atores envolvidos - configura o marco definidor do que denominamos Campo da Saúde do TrabaIhador (Lacaz, 1996; M endes \& Dias, 1991; M inayo-Gomez \& Thedim-Costa, 1997). A rigor, trata-se de um campo que não pode prescindir do potencial interpretativo das ciências sociais. É delas que se extrai um corpo de conceitose categorias centrais para uma abordagem interdisciplinar da intercessão entre as relações sociais e técnicas que configuram os processos de trabalho como condicionantes da saúde e da doença em coletivos de trabal hadores. Tais concei tos e categorias são decisivos para a interpretação da gênese dos agravos à saúde dos trabaIhadores e para a compreensão dos distintos níveis de determinação, imbricados na relação trabalho-saúde.

Ao introduzir a contribuição das ciências sociais na compreensão da saúde do trabalhador, o campo da saúde coletiva estabeleceu uma ruptura com as concepções hegemônicas da medicina do trabalho e da saúde ocupacional que, dentro de uma perspectiva positivista, formulam articulações simplificadas entre causa e efeito, desconsiderando a dimensão social e histórica do trabal ho e do processo saúde/doença. o novo marco ultrapassa, também, uma visão ambiental restrita aos locais de trabal ho que, sob uma compreensão unicausal, vincula uma doença a um agente. $\mathrm{Ou}$, mesmo indo além dessa concepção, avança para um enfoque multicausal, mas continua a interpretar a doença como resultante de um grupo de fatores de risco, em que a dimensão social é enten dida como variável socioeconômica individual, ou seja, como um mero componente a mais entre esses fatores.

N este artigo, propomo-nos a apresentar um panorama da apropriação do referencial das ciências sociais e humanas, na produção científica de autores latino-americanos no campo da saúde dos trabal hadores, observando, sobretudo, os avanços conseguidos nesse processo.

\section{Material e métodos}

A coleta de dados bibliográficos teve como fonte principal de referência artigos de periódicos indexados, teses de doutorado e dissertações de mestrado, produzidos nas duas últimas décadas, com particular ênfase nas publicações da área de saúde coletiva. Consultamos as seguintes fontes: o Banco de Dissertações e Teses organizado pela Coordenação de Aperfeiçoamento do Ensino Superior - Capes e pelo Instituto Brasileiro de Informação em Ciência e Tecnologia - IBICT; a Biblioteca Virtual em Saúde da Biblioteca Regional de M edicina - Bireme e o site do Scientific Electronic Library On-line SCIELO, organizado pela Fundação de Amparo à Pesquisa do Estado de São Paulo - Fapesp. Tentamos ainda localizar diretamente a produção científica dos programas de pós-graduação stricto sensu em saúde coletiva, mas seus acervos, na grande maioria, não se encontravam disponibilizados por meio eletrônico.

A produção acessível nos diversos bancos corresponde a diferentes períodos nesse intervalo de duas décadas, o que não permite uma visão de continuidade. A maior dificuldade encontrada, no entanto, se refere à fal ta de clareza e à pouca capacidade informativa dos resumos disponíveis nas fontes de dados. É importante ressaltar que, sobretudo, no caso das teses edissertações, grande parte dos resumos apresenta absoluta falta de rigor, de seqüência lógica e de precisão na linguagem. Seus conteúdos oscilam entre estender-se nos pressupostos ou na metodologia e deter-se na descrição dos resultados, tecendo apenas considerações de caráter geral.

Devemos evidenciar o que consideramos uma forte limitação do trabalho. Inicialmente, 
vislumbramos a possibilidade de obter material suficiente para estabelecer uma espécie de "estado da arte" da incorporação das ciências sociais no campo da saúde do trabalhador na América Latina. No entanto, frenteà pouca disponibilidade, nas bases de dados consultadas, de trabalhos dos estudiosos latino-americanos, a maior parte do material analisado provém de pesquisadores e pós-graduados brasileiros, em um universo bastante restrito. Para atender a nossa expectativa inicial, teria sido necessário um investimento, para o qual não tivemos tempo e nem recurso, de busca ativa nos próprios locais de produção das publicações de professores e alunos dos programas de pós-graduação de outros países latino-americanos, com área de concentração em saúde e trabalho. Sentimos, por exemplo, não poder contemplar, à altura, a produção existente na Universidade Autônoma M etropolitana - Xochomilco do M éxico, instituição pioneira nessa área, a não ser a que estava disponível nas bases de dados acima citadas.

A pesar de todas as limitações, a análise apresentada a seguir tem como fonte de dados, nada desprezível, um total de 404 estudos, dos quais, após uma leitura mais cuidadosa, selecionamos 102. Entre esses, nos detivemos naqueles que focalizavam temas específicos das ciências sociais e humanas ou incorporavam categorias, conceitos e noções próprios da área. A escolha pautou-se ainda na priorização dos trabalhos com texto completo ou daqueles cujos resumos forneciam elementos satisfatórios para a compreensão da temática abordada. Em sua imensa mai oria, tais estudos são resultados de pesquisas de cunho eminentemente qualitativo.

A abordagem do material constituiu-se, primeiramente, num tipo de diagnóstico que levasse em conta a natureza dos estudos; os enfoques presentes na formulação e no tratamento dos problemas; as temáticas predominantes; os novos objetos e as tendências teóricas de abordagem. Frente ao conjunto de conteúdos e temas aportados no material em análise e ponderadas as várias possibilidades de articulação, optamos por concentrá-los em grupos temáticos capazes de configurar um quadro inicial a ser ampliado. Sob essa lógica, adotamos a seguinte caracterização: reflexões sobre a construção e características do campo de conhecimento da saúde do trabal hador; política de saúde do trabalhador e práticas institucionalizadas; abordagens compreensivas; questões de gênero e temáticas decorrentes da precarização do mercado de trabalho.

\section{Análise da produção distribuída por temáticas e enfoques}

\section{Construção e características do campo de conhecimento da saúde do trabalhador}

Trata-se de um conjunto de estudos que caracterizam o contexto latino-americano que propiciou a emergência da área de saúde do trabaIhador, como campo de conhecimento. Abordam o distanciamento de concepções causais simplificadas - na prática ainda hegemônicas no entendimento do processo saúde-doença em coletivos de trabal hadores. Os autores fundamentam suas análises nos pressupostos das relações complexas entre os processos históricos, os processos de trabalho, o protagonismo dos trabal hadores e as repercussões dessas dinâmicas em sua saúde.

0 estudo mais completo sobre a trajetória do movimento que, no Brasil, contribuiu para a construção do conjunto de saberes e práticas da saúde do trabalhador foi realizado por Lacaz (1996). 0 autor parte de uma análise crítica das concepções - particularmente as de cunho higienista - e dos rumos seguidos nas formas de compreender os ambientes de trabalho e neles intervir, que precederam as visões sustentadas nos referenciais teóricos oriundos da medicina social latino-americana. Utilizando-se do modelo criado por Foucault para recuperar a história arqueológica das organizações e das idéias, interpreta as práticas discursivas sobre a relação trabalho-saúde na produção acadêmica, nos serviços e no movimento sindical. Avalia, entre outros aspectos, as repercussões que esse novo campo de conhecimento trouxe para o ensino e a pesquisa da saúde pública e da medicina preventiva e social.

Antecedendo a Lacaz, M endes e Dias (1991), efetuam uma revisão sintética da evolução dos conceitos e práticas que regem a medicina do trabalho, posteriormente ampliados com a compreensão introduzida pela saúde ocupacional, e cujas limitações a visão da saúde do trabalhador busca ultrapassar. Os autores, além de interpretarem as razões dessa evolução, descrevem o contexto em que a área de saúde do trabal hador surge, no Brasil, no espaço da saúde pública, esuas principais características. Destacam, entre outros aspectos, o empenho em contemplar os valores culturais dos trabalhadores concomitantemente com o estudo dos processos de trabalho.

$D$ atando da mesma época que o estudo de Lacaz, Cuellar e N oriega (1996), tendo como 
premissa que os processos produtivos constituem determinantes do conjunto de riscos e exigências a que estão submetidos os trabalhadores, analisam as repercussões na sua reprodução física e social, decorrentes da expansão e esgotamento de um modelo de acumulação vinculado à política neoliberal. Segundo os autores que focalizam a sociedade mexicana, cientes das peculiaridades das diferentes formações sociais -, as profundas transformações derivadas desse model o produzem impactos decisivos no terreno político, ideológico, sindical, cultural e, até, científico. Em sintonia com outros estudos anteriores, Cuellar (1995), N oriega (1995) e Sánchez \& Yanes (1995) ressaltam que as transformações provocadas pela gestão flexível da força de trabalho exigem incorporar, na investigação, novas dimensões para análise. Chamam atenção para a necessidade de contemplar, no estabelecimento de relações gerais entre processos produtivos e saúde, entre outros fenômenos: a deterioração e a agudização da heterogeneidade do mercado de trabalho; o crescimento de formas de subcontratação, do subemprego e do desemprego aberto; a queda da capacidade de negociação das entidades representativas dos trabalhadores e a el evação do número de trabalhadores desprotegidos socialmente. Consideram que a precarização do trabalho, em suas diversas faces, tende a converter-se em traço estrutural da economia e vem agravar velhos problemas de saúde e segurança, representando a seqüela mais marcante dessas mudanças. Concluem que, em decorrência desses fenômenos, cabe entender, tanto o elevado incremento de determinadas manifestações patológicas transtornos psíquicos e psicossomáticos - relacionadas com o stress e a fadiga, como o aumento significativo da morbi-mortalidade derivada da violência. Advertem que tais efeitos são cada vez mais comuns e menos diferenciáveis entre os setores industriais e os de serviços.

Finalmente, incluímos o estudo de Freitas (1996) que, a partir da temática específica dos acidentes químicos ampliados, explicita, como metodologia de investigação, a contribuição das ciências sociais para o desenvolvimento de análises de risco mais abrangentes. Estabelece o necessário diálogo entreas diversas abordagens das ciências sociais e as disci plinas das áreas tecnológicas e biomédicas, além de incorporar a participação tanto dos trabal hadores como das comunidades, por vivenciarem, no seu dia-a-dia, os riscos desses acidentes.

\section{Política de saúde do trabalhador e práticas institucionalizadas}

Referimo-nos aqui a alguns estudos que abordam questões relativas à compreensão do papel do Estado e das organizações da sociedade civil na formulação e implementação de políticas dirigidas ao controle e melhoria do quadro de saúde da população trabal hadora. Incluímos também publicações que anal isam as práticas implantadas em programas, centros de referência e órgãos de vigilância, sob a concepção de saúde do trabalhador, como movimento e prática social que engloba uma multiplicidade de sujeitos e espaços institucionais. Em seu conjunto, relacionam as possibilidades de êxito dessas ações à incorporação dos trabal hadores como sujeitos no espaço público, co-participantes legítimos nas decisões relativas a seu trabalho e a sua saúde, e atores fundamentais no exercício do controle social das medidas que Ihes são destinadas.

Partem de uma revisão crítica da política de saúde ocupacional vigente e propõem estratégias para a construção de uma política nacional de saúde do trabalhador cuja centralidade caberia ao setor saúde, com base nas premissas do movimento de Reforma Sanitária e na bagagem de conhecimentos e informações acumuladas em organismos internacionais e no movimento sindical ( $M$ endes, 1986).

Lacaz (1997) contextualiza a proposta programática da saúde do trabal hador no Brasil e descreve suas características como política social, a partir dos anos 80, identificando impasses para sua implementação. A ponta, também, os desafios institucionais e sociais para superar a crise da proposta no interior do setor saúde, que tem sua origem, como frisam Oliveira $\&$ Vasconcellos (2000), na forma marginal de tratamento dispensada à política nacional de saúde do trabalhador no âmbito da política nacional de saúde. Em conseqüência, dizem os autores, perpetua-se a histórica fragmentação de responsabilidades entre instituições e órgãos com atribuições de intervenção na área, embora algumas iniciativas de integração interinstitucional tenham surgido, como a criação da Comissão Intersetorial de Saúde do Trabalhador do Consel ho Nacional de Saúde e as recomendações contidas na N orma Operacional Básica do SUS, para uma articulação intersetorial que torne mais eficiente a execução das ações na área.

A inexistência de uma política estadual atuante é a tônica do diagnóstico de diversos estu- 
dos. Pereira (2001) interpreta a fragilidade da política de saúde do trabalhador no Ceará frente às transformações políticas, sociais e econômicas ocorridas nos últimos anos nesse Estado. Atribui tal fragilidade - refletida na dispersão e descontinuidade das ações - à morosidade do poder público eà própria desarticulação do movimento sindical.

No caso da Paraíba, essa situação se reverte quando, a partir da iniciativa da universidade, se desencadeia um movimento pela construção de uma política de saúde do trabalhador no âmbito estadual, que conseguiu aglutinar forças sociais e instâncias públicas implicadas na questão (Silva, 1998). Como o autor refere, o envolvimento dos diversos atores, embora de forma heterogênea, foi decisivo para conseguir avanços significativos na implantação de ações nesse campo. Sob a mesma perspectiva, CarvaIho (1997) destaca a criação e o desenvolvimento do serviço de referência em saúde do trabaIhador do Sistema Ú nico de Saúde - SUS, na Bahia, fruto do empenho de gestores institucionais e dirigentes sindicais. Com alto grau de legitimação entre os trabalhadores, esse serviço conquistou reconhecimento nacional devido à notória competência na implementação de suas atribuições.

No que diz respeito à questão específica da vigilância em saúde do trabal hador, constatamos uma expressiva contribuição, tanto no plano conceitual como na análise de experiências desenvolvidas no país. Para M achado (1996), a vigilância em saúde do trabalhador, no âmbito da saúde pública, é concebida como campo de prática articuladora de ações voltadas para 0 controle de atividades, riscos e agravos, tendo por referência, a relação entre processo de trabalho e saúde. Engloba diversos níveis de intervenção - empresa, ramo de atividade, território - bem como diferentes órgãos do poder público e instituições da sociedade civil. Com base em algumas experiências nacionais que alcançaram maior repercussão, 0 autor descreve as influências e características dessas práticas de vigilância, fundadas na intercessão de abordagens sociais, tecnológicas e epidemiológicas.

Nessa mesma linha, Pinheiro (1996) analisa o processo histórico que conduziu à emergência da vigilância em saúde do trabal hador no SUS, assinalando os principais marcos teóricos e as experiências nacionais e internacionais que inspiraram ou contribuíram para sua formulação. Ressalta a natureza anti-hegemônica e os limites dessa prática no Brasil, pelos conflitos que provoca, ao fundamentar-se na participação dos trabalhadores como sujeitos e protagonistas das estratégias de melhoria e transformação dos processos de trabal ho. A importância dessa participação é evidenciada em estudos que revelam avanços pontuais em estados, como Espírito Santo, onde se conseguiu estabelecer uma articulação entre o movimento sindical e determinadas instâncias públicas (Santos, 2001).

Oliveira (1994) já havia efetuado uma análise crítica e propositiva do modelo de intervenção do Estado brasileiro na inspeção dos ambientes de trabalho. Tendo por referência tal prática no Rio de Janeiro, discute al gumas alternativas visando tornar a inspeção do trabalho mais eficiente e consoante com as necessidades contemporâneas. Para tanto, aponta que seria preciso enfrentar, entre outras limitações, a baixa capacidade em atender às demandas, as deficiências de recursos materiais e humanos, a ausência de homogeneidade de critérios e métodos, a escassa participação dos trabalhadores nos processos de inspeção e a disputa contemporânea entre os setores da saúde e do trabal ho quanto às atribuições e ao poder de intervir nos ambientes laborais.

Ao questionar o pensamento dominante que submete os problemas contemporâneos da população trabalhadora a mitos tecnológicos e econômicos, Lieber (1991) introduz uma dimensão crucial na avaliação dos ambientes de trabalho. Em lugar de cingir-se a efetuar medições instrumentais precisas, seria mais correto - segundo o autor - contemplar, numa perspectiva mais ampla, a promoção da dignidade humana.

\section{Abordagens compreensivas}

Estas abordagens se distanciam de uma visão marxista meramente estrutural, mecanicista, em que os trabalhadores são concebidos apenas como força de trabalho, capital variável, agente econômico e coletivo subordinado ao capital, obscurecendo a influência das mediações culturais e existenciais. Propõem-se a compreender a práxis social dos trabalhadores, 0 sentido que conferem ao cotidiano do trabalho, suas formas de ser, sentir, perceber e agir. Focalizam o trabalhador como sujeito - com sua singularidade, com sua história - que, ao interagir com as condições objetivas, elabora categorias próprias de pensamento e ação.

Lopes (1999), em pesquisa ímpar, demarca as concordâncias e divergências nos modos de 
pensar as dimensões simbólicas, econômicas e políticas presentes nas relações entre processo de trabal ho e saúde. Confronta as diversas matrizes interpretativas, com o intuito de sublinhar a "centralidade dos sujeitos e da subjetividade operária", preocupação explicitada ou subjacente ao longo de sua tese. Insere a temática da saúde dos trabalhadores no interior das lutas travadas entre "a voz do dono" eo "dono da voz" (os detentores do capital e os produtores diretos) pelo controle e domínio do processo produtivo. Tendo o chão da fábrica como lugar crucial da experiência operária, o autor revela - com base em narrativas individuais, das quais extrai uma história coletiva, um significado compartilhado - as formas de resistência e de enfrentamento dos riscos, bem como dos agravos deles decorrentes. Esse estudo, ao desvelar o universo da experiência operária, oferece uma excelente contribuição à trajetória da saúde coletiva e do movimento sindical, particularmente - como 0 autor afirma - quando pretende assumir sua função de "intelectual orgânico" einterlocutor legítimo das "diversas vontades" presentes no cotidiano fabril.

É numa perspectiva similar que Sato (1997), em estudo etnográfico, analisa os processos interativos cotidianos de barganha que conduzem ao replanejamento do trabalho, no âmbito do chão da fábrica, como estratégia para prevenção dos problemas de saúde. Dos dois estudos emergem fragmentos de uma questão apontada por Lacaz (2000): a qualidade de vida como aspiração humana que não pode ser barrada no portão das fábricas. Efetivá-la supõe, para o autor, garantir canais efetivos de negociação, por meio dos quais a problemática da produtividade e da qualidade do produto seja subordinada à defesa da vida e da saúde.

Numerosos estudos inspiram-se nos postulados da Psicologia do Trabalho e, mais recentemente, da Psicodinâmica do Trabalho (Dejours \& Abdoucheli, 1994), em que a escuta do trabaIhador - a mediação da linguagem - é considerada essencial para apreender o significado que dá a suas vivências. Tais análises se propõem a compreender a dinâmica dos processos mobilizados pela confrontação do sujeito com a realidade do trabalho. Focalizam os conflitos surgidos do encontro entre um sujeito portador de história singular - que precede esse encontro e sua situação de trabalho fixada, em grande parte, independentemente de sua vontade. A questão do sofrimento, concebido como a vivência subjetiva intermediária entre o conforto ou bem-estar psíquico e a doença mental, permeia a maioria desses estudos. Tal compreensão do sofrimento implica um estado de luta do sujeito contra a organização do trabalho, cujas forças o impelem em direção à doença mental. N esse sentido, as investigações referidas a seguir centram-se em determinadas dimensões da organização do trabalho nas ocupações estudadas.

Foram desenvolvidas diversas pesquisas sobre profissionais de saúde, em continuidade ao trabalho pioneiro de Pitta (1989) sobre determinantes psicossociais dos agravos à saúde mental dos trabalhadores desse setor. Silva (1994) estuda a organização do trabal ho em enfermarias clínicas de um hospital público, tentando descobrir os fluxos de inventividade e prazer que o trabal ho produz. Constata, no entanto, que a intensa fragmentação das tarefas e as escassas oportunidades de partici pação, aliadas a conflitos corporativos e de identidade, tornam fugazes as possibilidades de expansão da vida e de redução do sofrimento.

São vários os trabal hos que focalizam os problemas de saúde dos trabalhadores da informática. Rocha (1996) estuda, especificamente, as contingências do trabalho de anal istas de sistemas. Analisa as manifestações de sofrimento, com repercussões na vida pessoal e familiar. E aponta suportes, no ambiente profissional eno âmbito familiar, capazes de minorar os efeitos adversos da situação laboral. Em outro estudo sobre essa categoria profissional, U chida (1996) investiga o impacto da informatização sobre a subjetividade, ressaltando a relação de ambigüidade que os analistas de sistema estabelecem com o computador. 0 desejo e o prazer de resolver enigmas confronta-se com o temor de viver "uma temporalidade destrutiva", gerando estratégias defensivas centradas no estabelecimento de limites no envolvimento com o trabalho. A relação entre prazer e sofrimento vivenciada por operadores de sistemas de computação é também estudada por Ribeiro (1992), levando-o a concluir que a organização do trabalho é muito mais nociva ao trabal hador do que as peculiaridades impostas pelas novas tecnologias.

As investigações referidas a seguir tratam da compreensão da experiência de tornar-se doente, vivida por trabalhadores acometidos por determinadas doenças do trabalho. Estabelecem inferências quanto às representações que essas experiências vêm moldando e sua influência na construção de identidades. 
Oliveira (1998) interpreta, numa perspectiva fenomenológica, o sentido que a leucopenia adquire, como doença do trabal ho. Aponta a insuficiência da narrativa da "condição leucopênica" construída pelos trabal hadores pela injunção da "experiência da enfermidade" com as narrativas produzidas pelo conhecimento médico e as emanadas de diversas fontes: instâncias públicas, empresas, sindicatos, entre outras. A presenta a necessidade de recorrer a outra abordagem, a narrativa do campo da Saúde do Trabalhador, em que ao modelo biomédico de entendimento do fenômeno da leucopenia associa-se o potencial explicativo das ciências sociais.

Verthein (2001) mostra, em estudo sobre portadores de lesões por esforços repetitivos LER, determinados componentes que confluem na cultura da doença e abal am os alicerces da identidade desses trabal hadores. Destaca o sofrimento provocado pela falta de reconhecimento social einstitucional das peculiaridades dessa enfermidade, o que - como ressalta M urofose (2000) - agrava as lesões e amplia as limitações impostas na vida cotidiana e laboral. À dor crônica alia-se a causada pelo descrédito, pela discriminação e, até mesmo, pelo tratamento recebido dos peritos do Instituto $\mathrm{N}$ acional de Seguro Social que culpam o próprio trabalhador pelo seu problema (Aguiar 1998). $\mathrm{Na}$ descaracterização do nexo das LER com as exigências do trabalho, esse Instituto recorre, como estratégia de redução de despesas, a discursos próprios da neuropsiquiatrização e da predisposição às doenças osteomusculares (Verthein \& M inayo-Gomez, 2001).

Diversas experiências de equipes multidisciplinares, como a analisada por M erlo, Jacques $\&$ H oefel (2001), vêm contribuindo para diminuir o sofrimento desses trabalhadores efomentar sua independência e autonomia. Representam soluções emergenciais, até o momento em que conquistas já obtidas pelos que realizam as funções mais repetitivas e monótonas (pausas regulares, limitação nas cadências, redução da jornada de trabalho) se estendam efetivamente a todos os trabalhadores (M erlo, 1990).

$\mathrm{Na}$ investigação de Thedim-Costa (1995), encontramos uma análise do confronto dos trabalhadores com o hidrargirismo, uma doença silenciosa e silenciada, durante mais de quatro décadas, numa empresa submetida, à época, a um conflituoso processo de vigilância. A autora reconstitui a gênese e os mecanismos de manuten ção desse silêncio coletivo e de imunidade ao controle público que permitiram, por tanto tempo, encobrir uma situação de extrema gravidade e abortar as tentativas de mobilização. M ostra, nesse universo hostil dominado pelo medo e pelos mais variados subterfúgios utilizados pela empresa, a dialética presente na recusa ou resistência dos trabalhadores a aceitar o diagnóstico contundente da doença. Premidos pela necessidade de manterem um trabal ho que contraditoriamente Ihes subtrai a saúde, os trabalhadores alternam atitudes isoladas de resistência e de conivência com os mecanismos instaurados para imobilizá-los diante da adversidade. As repercussões individuais, familiares e sociais compõem o quadro que a autora qualifica como a contaminação que se estende da fábrica à vida.

O caso particular das seqüelas decorrentes da violência inerente ao exercício de determinadas ocupações é anal isado por $V$ asconcelos (2000), em estudo sobre agentes de segurança penitenciária. Retrata um cotidiano, repetidamente conflitante com o trabal ho prescrito, que oscila entre o recurso a práticas repressivas e acordos com o coletivo dos presos. A violência que permeia tal atividade, segundo a autora, penetra a vida desses trabal hadores. Insegurança, angústia e medo invadem a casa e o mundo, 0 dentro e o fora, 0 antes e o depois do trabal ho.

U ma parte considerável dos estudos dessa natureza é suscetível de crítica, por adotar uma vertente fenomenológica que, na explicação dos fenômenos sociais, leva em conta apenas os significados construídos a partir das intenções dos sujeitos. Entretanto, não deixam de contribuir significativamente na compreensão dos processos, das relações e das situações em análise, sob a ótica dos próprios sujeitos.

\section{Questões de gênero}

Nos últimos anos, a perspectiva de gênero vem se consolidando nas investigações da área de saúde do trabalhador com vistas a promover o reconhecimento social ea visibilidade dos trabalhos executados pelas mulheres. A partir do pressuposto de que os papéis atribuídos a homens e mulheres são construções sociais que não se restringem às diferenças de sexo, essas investigações explicitam a necessidade de transformação das relações entre ambos, no trabaIho e na sociedade.

O estudo de Brito (1999), tendo como foco central a relação trabalho-saúde, constitui importante referência dessa temática transversal 
nas pesquisas sociológicas que visam romper com idéi as preconcebidas e naturalizadas a respeito da situação da mulher. Tem como eixo principal evidenciar as características e exigências do trabalho feminino e suas implicações para a saúde, como fatos coletivos e sociais que ultrapassam a percepção dual e estereotipada de oposição masculino/feminino, na qual a diferença não justifica a desigualdade, nem a igualdade nega as diferenças. A autora revela que nos espaços de trabalho existem também condições difer enciadas e assi métricas que submetem as mulheres a exposições e adoecimentos específicos. Dar visibilidade a esses problemas ecompreender o processo saúde-doença considerando a dimensão de gênero - como a autora se propôs na pesquisa sobre experiências coletivas objetivas e subjetivas de operárias da indústria química - significa questionar os lugares destinados às mulheres, as desigualdades artificialmente atribuídas à condição feminina. E que se refletem na tensão para conciliar trabalho, funções domésticas, maternais e reprodutivas; na subtração do tempo indispensável à manutenção da saúde física, emocional epsíquica; na exposição a diversas formas de violência, incluídas as de expressão simbólica.

N eves (1999) acentua a "centralidade da divisão sexual do trabalho", ao analisar a saúde mental de professoras primárias, suas vivências de prazer e sofrimento e as formas como constroem e desconstroem o sentido de um trabaIho desenvolvido em condições adversas. $\mathrm{Ob}$ serva que a "feminização" desse nível de magistério vem condicionada pela combinação das relações sociais de gênero e das necessidades de sobrevivência familiar. Elucida al gumas questões relativas à precarização e degradação do trabalho docente e suas implicações na identidade e na saúde dos profissionais envolvidos nessa atividade. Aponta um conjunto de fatores, referentes tanto à organização do trabalho como às condições materiais nas quais se realiza, que geram uma sensação generalizada de mal-estar próxima da síndrome patológica de burn- out. Destaca, particularmente, a desqualificação e a ausência de reconhecimento social, detectadas também em outros estudos sobre essa categoria profissional. Encontra movimentos de resistência contra a insatisfação, bem como dimensões de prazer, sobretudo na relação afetiva com os alunos e ao perceberem os resultados de suas atividades, o que foi observado por Nunes (2000) em investigação sobre o trabalho das merendeiras em escolas da rede pública.
A problemática da condição social feminina associada ao exercício profissional e seus reflexos na saúde de mulheres- trabal hadorasenfermeiras é enfatizada por Pedrosa (1999). Sua pesquisa integra o amplo leque de questões abordadas em el evado número de estudos sobre essa categoria profissional. Desde o de Douglas (1992), que questiona a prática da enfermagem na América Latina inspirada no modelo da medicina do trabalho, e defende a necessidade de adequá-la aos princípios da M edicina Social Latino-Americana, aos que analisam as representações sociais sobre $o$ trabal ho exercido em diversas instituições e especialidades (Oliveira, 1996; M atos Filho, 1997).

As repercussões na saúde das mulheres decorrentes da interseção entre a esfera produtiva e a doméstica também são apontadas por Rocha e Derbert-Ribeiro (2001). Em pesquisa sobre analistas de sistemas, ao estabelecer comparações entre homens e mulheres, demonstram a influência das dimensões de gênero - expressas na distribuição desigual defunções, tarefas e responsabilidades - no maior desgaste físico e psíquico. 0 caso específico do trabalho em horários não usuais (noturno) é elucidativo dessas diferenças, quando se evidencia que seus efeitos mais prejudiciais ocorrem em mulheres, especialmente nas que têm filhos (Rotenberg et al., 2001). Situação análoga é observada no setor agrário por Brochado (1998), ao analisar a problemática particular de saúde da mulher bóiafria, cortadora de cana, sobretudo no que se refere às formas de exploração do trabalho e de reprodução de sua condição feminina.

\section{Temáticas decorrentes da precarização do mercado de trabalho}

Incluímos aqui al gumas investigações sobre temáticas da maior relevância no atual cenário socioeconômico e político da América Latina ainda pouco abordadas na produção científica. Em grande parte, revelam diferentes seqüelas do quadro sombrio que apontamos na primeira parte deste artigo sobre as transformações que vêm acontecendo no mundo do trabalho.Trata-se de questões que têm adquirido maior visibilidade social, seja por afetarem grandes contingentes populacionais - como o desemprego; as limitadas possibilidades de acesso ao mercado formal de trabalho, cada vez mais seletivo; os padrões espúrios de terceirização e subcontratação - ou por contrariarem direitos fundamentais. Entre essas, onde a persistência do tra- 
balho infantil é paradigmática, incluem-se as situações que remetem à exclusão social significativos contingentes das classes populares, sobretudo da juventude, e à expansão de manifestações diversas de violência, na contra-mão do direito à vida.

Araújo (2001) avalia a terceirização implantada numa grande refinaria e identifica a "fratura social" gerada no seu interior, ao confrontar as condições de vida e trabal ho de contratados diretos e indiretos. Tais diferenças estendem-se, até mesmo, ao modo de gerenciamento dos sistemas de segurança. Conseguir uma mobilização que integre o conjunto dos trabaIhadores, a despeito do tipo de vínculo, para se opor a esse padrão de terceirização representa na opinião do autor - um grande desafio para o movimento sindical, com escassas possibilidades de sucesso no curto prazo.

0 desemprego de longa duração, em seus reflexos na sociabilidade e na saúde, é objeto de estudo de Selligmann-Silva (2001). Sua investigação corrobora as interpretações encontradas em estudos internacionais, citados pela autora, sobre as repercussões psi cossociais e psi copatológicas da subtração do emprego. Tais impactos correspondem a processos de degradação da saúde mental que podem começar em situações desfavoráveis de trabal ho e ter continuidade ao longo do período de inatividade forçada. N essa trajetória, a autora identifica várias fases - retraimento, afastamento e isolamento social que afetam, de forma concomitante, a vida material, a sociabilidade e a subjetividade. M ostra que essa dinâmica, dominada pelo desânimo, pode levar a estados graves de depressão. Os múltiplos e complexos mecanismos de exclusão social, acionados pelo prolongado afastamento das atividades laborais, segundo a autora, exigiriam a implantação de programas intersetoriais executados por uma rede articulada de agências. A seu ver, as ações terapêuticas dos serviços de atenção à saúde dos trabalhadores deveriam ser conectadas às de apoio social e formação, com o propósito de propiciar a reinserção laboral e comunitária. A premência de incorporar essa questão na agenda dos programas de saúde do trabal hador também é apontada por Sant'Anna (2000), ao analisar a diversidade de estratégias organizativas e de geração de renda encontradas por trabal hadores desempregados num município que passou por diversas ondas de demissão em massa.

0 dilema enfrentado pelos jovens dos segmentos de maior vulnerabilidade social - ur- dido na fragilidade das políticas públicas voltadas para a juventude - entre aceitar um trabalho precário ou inserir-se em atividades ilegais, particularmente no narcotráfico, foi investigado por M eirelles (1998). A autora identifica uma elevada concentração de adolescentes que acabam optando pela segunda alternativa, em graus diversos de envolvimento. Ressalta a predominância de uma visão hedonista e imediatista, engendrada num presente totalizante, que ofusca a idéia de projeto de futuro e tem, como desfecho, a morte prematura.

Diversas iniciativas endereçadas a esses jovens, desenvolvidas por organizações não-governamentais, $\mathrm{ONGs}$, vêm abrindo um espaço para a ruptura desse dilema aprisionador. U m campo produtor de novas subjetividades, no embate contra as teias do conformismo ao meio social. Pesquisas de Lima (2002) e Costa (2001) revelam a importância de alguns desses projetos, considerados verdadeiros laboratórios sociais, que fomentam novas formas de sociabilidade, além da perspectiva profissionalizante. Tais investigações não se detêm apenas na reflexão sobre situações-problema. Propõem-se a dar visibilidade a experiências de sucesso que, por meio de parcerias com o Estado, podem subsidiar políticas de atenção a essa juventude.

A gravidade da incorporação precoce de crianças e adolescentes no mercado de trabalho, perante a qual, como argumentam M inayo-Gomez \& M eirelles (1997), não se sustenta qualquer justificativa social, éilustrada em dois estudos. Dias et al. (2002) mostram as condições degradantes presentes na produção artesanal de carvão vegetal, em que esse segmento da população é, ainda hoje, forçado a inserir-se. Situação semelhante é apresentada por Abreu (2001) em relação a adolescentes que, na condição de "empregados irregulares, com ínfimas remunerações, realizam "atividades informais para terceiros" na lavoura da cana-de-açúcar. Jornadas exaustivas de trabalho, em condições aviltantes, concorrem para a conformação de uma "vitrine de riscos e acidentes".

\section{Considerações finais}

Elaboramos apenas uma visão panorâmica das características da produção científica que, sob referenciais das ciências sociais, contribui para a definição e conformação do campo da saúde do trabal hador. Essa versão sintética corresponde a uma das leituras possíveis, após a tarefa de 
selecionar e tentar aproveitar os conteúdos das publicações a que tivemos acesso, consideradas as limitações já referidas.

Como evidencia este trabal ho, o campo de conhecimento denominado "saúde do trabaIhador", da mesma forma que outros da saúde coletiva, requer a mediação explícita ou implícita do corpo conceitual das ciências sociais e humanas. Tal aporte retira o caráter eminentemente higienista conferido à relação trabal hosaúde, a partir do momento em que o trabalho, concebido como uma categoria social, é resultante de um emaranhado de relações econômicas, sociais, políticas e tecnológicas que se realizam de forma conflituosa e interdependente.

A mudança e ampliação dos objetos de estudo que se incluem no campo são notórias na década de 1990, principalmente a partir da sua segunda metade, com a introdução do instrumental das ciências sociais. Entre outras razões, podem ser atribuídas ao fato de que, nesse período, começam a tornar-se visíveis os resultados da incorporação dessa abordagem na área de concentração de al guns programas de pósgraduação ou, individualmente, por pesquisadores de outros programas ou áreas. Além das temáticas relativas à política e serviços de atenção à saúde dos trabalhadores, intensificaramse as pesquisas qualitativas e começaram a ser contem pladas categorias de trabalhadores até então não estudadas. As pesquisas relativas ao setor de serviços - que enfatizam, na análise dos processos de trabal ho, as questões derivadas da organização do trabalho - adquirem importância significativa em comparação às que, de cunho eminentemente epidemiológico, vinham sendo efetuadas sobre trabalhadores industriais, focalizando sobretudo os riscos e agravos decorrentes dos ambientes de trabalho.
A tônica predominante nas investigações, quer na definição dos objetos de estudo e na metodologia adotada, quer na interpretação dos resultados, é contribuir para a mudança das situações encontradas. 0 caráter propositivo dessas pesquisas contrasta, no entanto, com 0 escasso empenho em efetivar as transformações necessárias, num descompasso entre avanço do conhecimento e perpetuação das práticas instauradas.

O bserva-se, finalmente, na produção das duas últimas décadas, um distanciamento das explicações globalizantes, das macroteorias e das metanarrativas. Em seu lugar, tornam-se mais abundantes as explicações de médio alcance que contemplam diversidades de mediações, temporalidades diferentes entre os níveis de análise e especificidades tanto das questões como dos sujeitos sociais estudados. Tal tendência vem sofrendo alguns questionamentos por autores que defendem a necessidade de adotar enfoques totalizadores, que ultrapassem formulações fragmentadas da realidade, reflexos de visões "pós-modernas". Consideramos improcedente entrar numa discussão que, a nosso ver, traduz uma falsa polarização, já que não correspondem a posições obrigatoriamente excludentes e, em grande medida, podem trazer contribuições complementares. Concluímos, em sintonia com Cuellar (1995), pela necessidade de diagnosticar - na atual fase do desenvolvimento capitalista, nas diversas formações econômicas latino-americanas - os problemas de saúde relacionados ao trabal ho que adquirem maior relevância social. É neles, e preferentemente nos menos conhecidos, que o esforço intelectual deveria se concentrar. 


\section{Referências bibliográficas}

Abreu CCR 2001. 0 trabalho infanto-juvenil e sua erradicação: repercussões e perspectivas. Dissertação de mestrado. Centro de Ciências do H omem, Universidade Estadual do Norte Fluminense, Campos dos Goytacazes (RJ). 113pp.

Aguiar M CF 1998. 0 trabalhador sem seu trabalho: um estudo sobre a identidade de trabalhadores afastados por adoecimento profissional. Dissertação de mestrado. Departamento de Psicologia, U niversidade Federal do Espírito Santo, Vitória. 159pp.

Araújo AJS 2001. Paradoxos da modernização: terceirização e segurança em refinaria de petróleo. Tese de doutorado. Escola Nacional de Saúde Pública, Fiocruz, Rio de Janeiro. 347pp.

Brito JC 1999. Saúde, trabalho e modos sexuados de viver. Fiocruz, Rio de Janeiro. 179pp.

Brochado OC 1998. Trabalho, saúde e reprodução da vida: a mulher bóia-fria no mundo cindido de Paraguaçu Paulista. São Paulo. Dissertação de mestrado. Faculdade de Filosofia, Letras e Ciências H umanas, Universidade de São Paulo, São Paulo. 130pp.

Carvalho GBM 1997. Saúde do trabalhador na Bahia: 0 caso do CESAT, 1988-1996. Dissertação de mestrado. Instituto de Saúde Coletiva, U niversidade Federal da Bahia, Salvador. 104pp.

Costa EA 2001. Quebrando as barreiras da impossibilidade: a contribuição das ON Gs para a inserção social de jovens em situação de risco social na passagem para a maioridade. Dissertação de mestrado. Escola N acional de Saúde Pública, Fiocruz, Rio de Janeiro. 99pp.

Cuellar R 1995. Salud en el trabajo. realidad o método? Salud de los Trabajadores 3(2):69-81.

Cuellar R \& Noriega M 1996. M odernización, condiciones de trabajo y salud. Salud de los Trabajadores 4(1): 5-15.

Dejours C \& Abdoucheli E 1994. Psicodinâmica do trabaIho: contribuições da escola dejouriana à análise das relações prazer, sofrimento e trabalho. Ed. Atlas. São Paulo. 145pp.

Dias EC, Assunção AA, Guerra CB \& Prais HAC 2002. Processo de trabal ho e saúde dos trabal hadores na produção artesanal de carvão vegetal em M inas Gerais, Brasil. Cadernos de Saúde Pública 18(1):269-277.

D ouglas JL 1992. Contribuição para a caracterização da enfermagem que atua na assistência à saúde do trabaIhador na América Latina. Dissertação de mestrado, Faculdade de Saúde Pública, Universidade de São Paulo, São Paulo. 157pp.

Ferreira EF 1998. Análise do processo de discussão/construção de uma política de saúde do trabalhador. Dissertação de mestrado. Faculdade de Serviço Social, Universidade Federal da Paraíba, João Pessoa. 220pp.

Freitas CM 1996. Acidentes químicos ampliados: incorporando a dimensão social nas análises de risco. Tese de doutorado. Escola Nacional de Saúde Pública, Fiocruz, Rio de Janeiro. 231pp.

Lacaz FAC 1996. Saúde do trabalhador: um estudo sobre as formações discursivas da academia, dos serviços e do movimento sindical. Tese de doutorado. Faculdade de Ciências M édicas, Universidade Estadual de Campinas, Campinas. 435pp.

Lacaz FAC 1997. Saúde dos trabalhadores: cenários e desafios. Cadernos de Saúde Pública 13(Supl. 2):7-20.
Lacaz FAC 2000. Q ualidade de vida no trabalho e saúde/ doença. Ciência \& Saúde Coletiva 5(1):151-162.

Laurell AC 1985. Saúde e trabalho: os enfoques teóricos, pp. 255-276. In Nunes ED (org.). As ciências sociais em saúde na América Latina. OPAS, Brasília.

Lieber RR 1991. Saúde no trabalho rumo ao ano 2000: tendências na avaliação dos ambientes de trabalho. Revista Brasil. Saúde O cupacional 19(74):52-60.

Lima SM 2002. Modos de subjetivação na condição de aprendiz: uma análise de perspectivas educativas na composição saúde, trabalho e arte. Tese de doutorado. Escola N acional de Saúde Pública, Rio de Janeiro. $145 p$.

Lopes JC 1999. A voz do dono e o dono da voz: trabalho, saúde e cidadania no cotidiano fabril. Tese de doutorado. Faculdade de Ciências M édicas, U niversidade Estadual de Campinas, Campinas. 391pp.

M achado JM H 1996. Alternativas e processo de vigilância em saúde do trabalhador: a heterogeneidade da intervenção. Tese de doutorado. Escola Nacional de Saúde Pública, Fiocruz, Rio de Janeiro. 166pp.

M atos Filho AS 1997. A saúde e o processo de trabalho do enfermeiro: um estudo de caso em Jequié. Jequiezinho - RJ. Escola de Enfermagem, Universidade do Rio de Janeiro, Rio de Janeiro. 148pp.

M endes R 1986. D outrina e prática da integração da saúde ocupacional no setor saúde: contribuição para a definição de uma política. Tese de livre docência. Faculdade de Saúde Pública, U niversidade de São Paulo, São Paulo. 384pp.

M endes R \& Dias EC 1991. Da medicina do trabalho á saúde do trabalhador. Revista de Saúde Pública 25(5): 341-49.

M eirelles ZV 1998. Vida e trabalho de adolescentes no narcotráfico numa favela do Rio de Janeiro. Dissertação de mestrado. Escola N acional de Saúde Pública, Fiocruz, Rio de Janeiro. 99 pp.

Merlo ARC 1999. A informática no Brasil: prazer e sofrimento no trabalho. Ed. U niversidade/U niversidade Federal do Rio Grande do Sul, Porto Alegre. 270 pp.

M erlo ARC, Jacques M GC \& H oefel M GL 2001. Trabalho degrupo com portadores de LER/DORT: relato de experiência. Psicologia \& Reflexão Crítica 4(1):253-258.

M inayo-Gomez C \& M eirelles ZV 1997. Crianças e adolescentes trabalhadores: um compromisso para a saúde coletiva. Cadernos de Saúde Pública 13(Supl. 2): 135-140.

M inayo-Gomez C \& Thedim-Costa SM F 1997. A construção do campo da Saúde do Trabalhador: percurso e dilemas. Cadernos de Saúde Pública 13(Supl. 2): 21-32.

M urofose NT 2000. M udanças no trabalho e na vida de bancários ocasionadas por lesões por esforços repetitivos - LER, Cascavel - PR. Dissertação de mestrado. Faculdade de Enfermagem, U niversidade de São Paulo, Ribeirão Preto. 207pp.

Neves M YR 1999. Trabalho docente e saúde mental: a dor e a delícia de ser (tornar-se) professora. Tese de doutorado. Instituto de Psiquiatria, U niversidade Federal do Rio de Janeiro, Rio de Janeiro. 277pp.

N oriega M 1995. La realidad latinoamericana frente a los paradigmas de investigación en salud laboral. Salud delos Trabajadores 3(1):13-20. 
Nunes BO 2000. 0 sentido do trabalho para merendeirase serventes em situação de readaptação nas escolas públicas do Rio de Janeiro. Dissertação de mestrado. Escola Nacional de Saúde Pública, Fiocruz, Rio de Janeiro. 161pp.

Oliveira JR 1996. Saúde, tuberculose e condições de trabaIho: representações dos trabal hadores de enfermagem. Dissertação de mestrado. Escola de Enfermagem, Universidade Federal do Rio de Janeiro, Rio de Janeiro. 141pp.

Oliveira LC 1998. A epidemia de um estigma: leucopenia e benzenismo entre trabalhadores do pólo petroquímico de Camaçari-BA. Dissertação de mestrado. Ciências Sociais, Universidade Federal da Bahia, Salvador. 201pp.

Oliveira LSB 1994. A intervenção do Estado nos ambientes de trabalho no Brasil e análise crítica da prática da Delegacia Regional do Trabalho do Rio de Janeiro na década de 1980. Dissertação de mestrado. Escola Nacional de Saúde Pública, Fiocruz, Rio de Janeiro. 237pp.

Oliveira M HB \& Vasconcellos LCF 2000. As políticas públicas brasilei ras de saúde do trabal hador: tempos de avaliação. Saúde em Debate 24(55):92-103.

Pedrosa LAK 1999. A saúde das mulheres-trabalhadoras enfermeiras: o real e o vivido. Tese de doutorado. Faculdade de Enfermagem, Universidade de São Paulo, São Paulo. 181pp.

Pereira APM 2001. Políticas públicas de saúde do trabaIhador no Estado do Ceará. Dissertação de mestrado. Programa de Pós-Graduação em Saúde Pública, Universidade Estadual do Ceará, Fortaleza. 150pp.

Pitta AM F 1990. H ospital: dor e trabalho como ofício. Hucitec. São Paulo. 198pp.

Pinheiro TM M 1996. Vigilância em saúde do trabalhador no Sistema Ú nico de Saúde: a vigilância do conflito e o conflito da vigilância. Tese de doutorado. Faculdade de Ciências M édicas, Universidade Estadual de Campinas, Campinas. 203pp.

Rocha LE 1996. Estresse ocupacional em profissionais de processamento de dados: condições de trabalho e repercussões na vida e saúde dos analistas de sistemas. Tese de doutorado. Faculdade de M edicina, U niversidade de São Paulo, São Paulo. 285pp.

Rocha LE \& Derbert-Ribeiro M 2001. Trabalho, saúde e gênero: estudo comparativo sobre analistas de sistemas. Revista de Saúde Pública 35(6):539-547.

Rotenberg L, Portela LC, M arcondes WB, M oreno C \& Nascimento CP 2001. Gênero e trabalho noturno: sono, cotidiano e vivências de que troca a noite pelo dia. Cadernos de Saúde Pública 17(3):639-649.
Sanchez L \& Yanes L 1995. El abordaje de la salud de los trabajadores en el escenario de reajuste económico, la reconversión industrial y los cambios tecnológicos. Salud de los Trabajadores 3(1):35- 42 .

Sant 'Anna FCR 2000. Desemprego e saúde: dilemas e perspectivas nas trajetórias dos trabalhadores do Estaleiro Verolme, Angra dos Reis - RJ. 85pp.

Santos APL 2001. Entre o imediatismo e o planejamento: 0 desafio da construção da vigilância em saúde do trabalhador no Centro de Referência em Saúde do Trabalhador em Espírito Santo. Dissertação de mestrado. Escola N acional de Saúde Pública, Fiocruz, Rio de Janeiro. 148pp.

Sato L 1997. Astúcia e ambigüidade: as condições simbólicas para o replanejamento negociado do trabalho no chão da fábrica. Tese de doutorado. Instituto de Psicologia, Universidade de São Paulo, São Paulo. 198pp.

Selligmann-Silva E 2001. Desemprego e psicopatologia da recessão, pp. 219-254. In Borges LH, M oulin M GB \& A raújo M D (orgs.). Organização do trabalho e saúde: múltiplas relações. EDUFES, Vitória.

Silva CO 1994. Curar adoecendo: um estudo do processo de trabalho hospitalar em busca da saúde, da inventividade e da vida. Dissertação de mestrado. Escola Nacional de Saúde Pública, Fiocruz, Rio de Janeiro. 246pp.

Silva EF 1998. Análise do processo de discussão/construção de uma política de saúde do trabalhador. Dissertação de mestrado. Faculdade de Serviço Social, Universidade Federal da Paraíba, João Pessoa. 220pp.

Thedim-Costa SM F 1995. M ercúrio: perigo e silêncio. Dissertação de mestrado. Escola N acional de Saúde Pública, Fiocruz, Rio de Janeiro. 110pp.

U chida S 1996. Temporalidade e subjetividade no trabalho informatizado. Tese de doutorado. Instituto de Psicologia, U niversidade de São Paulo, São Paulo. 232pp.

Vasconcelos ASF 2000. A saúde sob custódia: um estudo sobre agentes de segurança penitenciária no Rio de Janeiro. Dissertação de mestrado. Escola $\mathrm{N}$ acional de Saúde Pública, Fiocruz, Rio de Janeiro. 65pp.

Verthein M AR 2001. Jogos de poder instituindo saber sobre as lesões por esforços repetitivos: as redes discursivas da recusa do nexo. Tese de doutorado. Escola N acional de Saúde Pública, Fiocruz, Rio de Janeiro. 215pp.

Verthein MAR \& M inayo-Gomez C 2001. As armadilhas: bases discursivas da neuropsiquiatrização das L.E.R. Ciência \& Saúde Coletiva 6(2):457-470.

Artigo apresentado em 21/11/2002

Aprovado em 6/1/2003

Versão final apresentada em 27/1/2003 